\title{
"POR UN BESO DE TU BOCA": ASSISTÊNCIA À SAÚDE BUCAL INFANTIL NA REVISTA SALUD Y SANIDAD DA COLÔMBIA (DÉCADA DE 1930)
}

\author{
"For a kiss from your mouth": Assistance to infant \\ health in the magazine Salud y Sanidad of Colombia \\ (Decade of 1930)
}

\author{
Iranilson Buriti de Oliveira* \\ Lais Vasconcelos Santos ${ }^{* *}$
}

\begin{abstract}
RESUMO
O presente artigo realiza uma análise dos discursos médicohigienista de profissionais dentistas sobre as crianças colombianas na década de 1930 veiculadas na Revista Salud y Sanidad. Para tanto, uma pesquisa documental de abordagem bibliográfica e exploratória foi desenvolvida. $\mathrm{Na}$ análise, dialogamos com a teoria que repensa os conceitos de leitura e de apropriação de discursos construídos pela Nova História Cultural, o que nos possibilitou problematizar as formas de ler e os modos de prescrever o corpo higienizado, civilizado, moderno e educado na ótica da assistência à saúde bucal infantil. Considera-se que a compreensão da saúde bucal como uma estratégia adotada pelo Estado colombiano em prol da modernidade de seus cidadãos, desdobra-se no entendimento de que as crianças foram alvos de práticas assistencialistas e de métodos normativos. Estes métodos são encontrados: 1) em atividades familiares; 2) em atividades escolares e 3 ) em atividades profissionais, nas quais se situam os dentistas, inseridos nos espaços escolares para assistir, cuidar e prevenir doenças, promovendo regulamentos sobre corpos
\end{abstract}

*Pós-Doutor em História das Ciências e da Saúde. Professor da Universidade Federal de Campina Grande/UFCG; bolsista de Produtividade do CNPq. Condomínio Nações Residence Privê. BR 104, Km 119, 58117-000 - Lagoa Seca - PB - Brasil. E-mail: iburiti@yahoo.com.br

** Mestranda em História pelo Programa de Pós-Graduação em História da UFCG. Bacharela em Enfermagem pela UFCG. E-mail: lais_lvs@ hotmail.com 
saudáveis por meio de avaliações clínicas e de incentivo a práticas como a escovação.

Palavras-chave: Saúde Bucal; Crianças; Práticas Assistencialistas

\begin{abstract}
This article analyzes the medical-hygienist discourses of dental professionals on Colombian children in the decade of 1930, published in the magazine Salud $y$ Sanidad. For that, a documentary research of bibliographical and exploratory approach was developed. In the analysis, we dialogued with the theory that rethinks the concepts of reading and appropriation of discourses constructed by the New Cultural History, which enabled us to problematize the ways of reading and the ways of prescribing the sanitized, civilized, modern and educated body in the optics assistance to children's oral health. It is considered that the understanding of oral health as a strategy adopted by the Colombian State in favor of the modernity of its citizens, unfolds in the understanding that the children were targets of assistentialists practices and normative methods. These methods are found: 1) in family activities; 2) in school activities; 3) in professional activities, in which the dentists are located, inserted in the school spaces to watch, care and prevent diseases, promoting regulations on healthy bodies through clinical evaluations and to encourage practices such as brushing.
\end{abstract}

Keywords: Oral Health; Children; Assistentialists practices

\title{
Introdução - Caminhadas pelo contexto histórico- social
}

Este artigo pretende dar visibilidade às conexões entre saúde da criança e práticas educativas na Colômbia, tendo como fonte a Revista Salud y Sanidad, periódico de circulação nacional colombiana da década de 1930, dando especial atenção aos cuidados de assistência à infância com a saúde bucal. Desde o final do século XIX, a América Latina e o Caribe experimentavam um processo de aumento populacional, resultante tanto do crescimento vegetativo da população quanto de migrações (endógenas e exógenas). Com essa mudança na estrutura da população, vislumbrou-se o crescimento 
urbano que passou a ser alvo de preocupação do estado no sentindo de buscar a modernização, a melhoria na infraestrutura urbana principalmente nas cidades principais de cada nação, o controle social e a divulgação de novas práticas educativas para controlar o corpo social. Para tanto, a adoção de estratégias políticas (públicas e privadas), educativas, higienistas e morais foram aplicadas para modelar, orientar cidadãos, trabalhadores e controlar as enfermidades sociais visando o progresso nacional. ${ }^{1}$

Nesse contexto histórico-social, uma nova realidade emerge para assustar a população: a proliferação crescente de enfermidades ${ }^{2}$. Percebe-se nesse cenário a impossibilidade dos profissionais da saúde em estabelecer limites e distinguir o conhecimento científico dos preconceitos e preceitos morais de sua época. Esta situação históricosocial contribui para nortear suas práticas profissionais diante dos hábitos e comportamentos arraigados da população, e a tentativa de implantar um conjunto de novos hábitos e atitudes baseados nas tônicas do moderno e do progresso. ${ }^{3}$ Mudar os costumes prejudiciais à saúde era urgente e necessário. Assim, um conjunto de saberes emerge para educar, domesticar e habituar os sujeitos na busca de corpos disciplinados.

EDUCAR. Percebe-se nas intervenções médicas a vertente política aliada ao poder estatal, para controlar e intervir na sociedade. Intervir para mudar, eis a tônica de profissionais da saúde preocupados com o mal-estar e a vulnerabilidade da população. Intervir para educar, para inculcar na população, desde a mais tenra idade, os hábitos saudáveis. Tendo a higiene, a civilização e o progresso presença marcante nos discursos de médicos, de dentistas e de sanitaristas que objetivavam regular os comportamentos sanitários,

1 ARAMÉNDIZ, Miguel Antonio Suárez; MENDONZA, Edwin Andrés Monsalvo. La higiene y el progreso. La institucionalización de la burocracia sanitaria en Manizales. 1920-1940". Anuario de Historia Regional y de las Fronteras, v. 18, n.1, p.99-125, 2013.

$2 \mathrm{O}$ termo 'enfermidades sociais' foi utilizado por médicos até inicio do século XX para referir-se tanto a doenças contagiosas como a sífilis e tuberculose quanto aos males sociais que afetavam amplos setores da população.

3 NOGUERA, Carlos Ernesto. Luta Antialcoólica e Higiene Social na Colômbia, 18861948. In: Gilberto Hochman; Diego Armus (Org.). Cuidar, Controlar, Curar: ensaios históricos sobre saúde e doença na América Latina e Caribe. Rio de Janeiro: Editora Fiocruz, 2004. p.99-124. 
a tônica era educar a população e aplicar normas sanitárias que regulassem os sujeitos. ${ }^{3}$

DOMESTICAR. Entre os séculos XIX e XX se fundamentou o ideal da nação colombiana tendo como parâmetros os discursos da educação, da higiene e do progresso. Esse discurso circulava não somente na cartografia colombiana, mas em toda a América Latina, a exemplo do Brasil, Argentina e México, apenas para citar alguns países. A construção da imagem de uma nova nação passou a ser divulgada em revistas e periódicos, circulando em manuais pedagógicos e sendo apropriados, em maior ou menor grau, por médicos, odontólogos, professores, políticos e autoridades em geral. Para tanto, necessitava-se fortalecer a escola e a família, pois através destas instituições se podiam divulgar e formar indivíduos preocupados com o progresso. ${ }^{4} \mathrm{E}$ um alvo fundamental para ações destacadas nos discursos políticos e de higienistas eram as crianças, necessitando, assim, de um corpo domesticado pelos discursos dessas autoridades. Portanto, intervenções ortopédicas deveriam ser pensadas e aplicadas, sendo a família e a escola os espaços ideais para formar e educar os novos cidadãos. ${ }^{5}$ Nessas intervenções, ocorre paulatinamente uma "alteração da relação do homem com sua própria boca”. Kovaleski, Freitas e Botazzo colocam que:

Como certo tipo de localização (ou atributo de materialidade corpórea), a boca é disciplinada, vigiada, como o restante do corpo, por alguém que está no alto do panóptico bemthamiano ou pode não estar. É da boca disciplinada aue tratamos. A boca no corpo vigiado, como se a norma social fosse natural e imanente.

4 BARBOSA, Alejandra María Valverde. La educación en Colombia: un proyecto de nación moderna entre la higiene, la moral y la pedagogia. Intertextos: cuadernos del programa de comuncación social., n.2, p.99-106, 2007.

5 GONZALES, Ángela Lucia Agudelo. Regenerar e higienizar. El papel desempeñado por la mujer y la niñez en Barranquilla 1900 - 1945. Memorias, Año 5, n. 9, p.94-109, 2008.

6 KOVALESKI, Douglas Francisco; FREITAS, Sérgio Fernando Torres de; BOTAZZO, Carlos. Disciplinarização da boca, a autonomia do indivíduo na sociedade do trabalho. Ciênc. saúde coletiva, Rio de Janeiro, v. 11, n. 1, p. 97-103, Mar. 2006. P.101. 
HABITUAR. Frente a essas ações voltadas para as crianças, encontramos prescrições e diagnósticos sobre a infância presentes em discursos de médicos, dentistas e professores, dentre outros profissionais, com o propósito de intervenções pedagógico-sanitárias em meninos e meninas. O objetivo era criar hábitos ditos saudáveis, "habituando-os" a uma vida regrada pelas normas de uma sociedade culta e letrada. A esse respeito, Nunes aborda que:

O desejo era atuar sobre o individuo mesmo antes do seu nascimento até sua juventude, no sentido de formar, seja por meio da saúde e higiene, da escolarização e educação, ou por meio da assistência um determinado tipo de futuro cidadão, caracterizado como laborioso, civilizado, biologicamente saudável, apto para a vida moderna como trabalhador- no caso dos setores populares- o como condutor dos destinos sociais- no caso dos setores da elite. ${ }^{7}$

Nesta direção, ao estudarmos acerca das práticas higienistas e assistencialistas em espaços escolares ${ }^{8}$, eis que surgiu a indagação de como aconteceram as ações de profissionais dentistas para intervir na saúde bucal dos escolares, já que possuir um sorriso e uma boca perfeitos era condição de progresso e de modernidade. Assim, este trabalho se propõe a analisar a circulação do discurso higienista de profissionais dentistas sobre as crianças colombianas na década de 1930. Para tanto, foi realizada uma pesquisa documental de abordagem bibliográfica que adotou como fonte a Revista Salud y Sanidad, publicação colombiana que circulou na década de 1930 nos diversos departamentos da Colômbia. Essa revista constitui uma

7 NETTO NUNES, Eduardo Silveira. "La infancia latinoamericana y el Instituto Internacional Americano de Protección a la Infancia (1916-1940)". In: SOSENSKI, Susana; ALBARRAN, Elena Jackson (org.). Nuevas miradas a la historia de la infancia en América Latina: entre prácticas y representaciones. Ciudad de México, D.F., México: UNAM, Instituto de Investigaciones Históricas, 2012, p. 293-325.

8 Esta discussão foi possibilitada a partir das atividades do projeto de pesquisa "Mamíferos Desdentados8": educação, sensibilidades e produção de corpos saudáveis no Brasil e 'na Colômbia (1918-1946), vinculado ao CNPq/UFCG. 
publicação mensal do Departamento Nacional de Higiene, de Bogotá, organizada pela "Seção de Ancilostomose", e foi dirigida por Ricardo Bonilla. Sob o slogan "MELHOR É PREVENIR QUE CURAR", nesse periódico circulavam matérias relacionadas à propagação da higiene pública e privada, escritos falando de enfermidades, sanitarismo e temáticas de interesse à saúde da população em geral. Publicava pequenas novelas voltadas para o cuidado da criança, a exemplo da novelinha "Por um Beijo", a ser discutida posteriormente, e que dá título a este artigo.

O recorte temporal adotado justifica-se por ser nesse período onde percebemos a emergência de medidas assistencialistas referentes à saúde pública que se desdobram em cuidados com a saúde bucal. $\mathrm{Na}$ análise do periódico, iremos dialogar com a teoria que repensa os conceitos de leitura e de circulação de discursos construídos pela Nova História Cultural, para isso, nos apropriamos do conceito de leitura como um modo de busca, pois o ato de ler, como aponta Chartier é "uma prática criativa que inventa significados e conteúdos singulares, não redutíveis às intenções dos autores dos textos ou dos produtores dos livros". 9 É, dessa forma, uma operação, uma maneira de ler a escrita médico-odontológica sobre a educação como uma "prática cultural controlada por outras práticas, que ao mesmo tempo diagnostica e prescreve". 10

Para dar conta da circulação de ideias sobre saúde bucal, lançamos mão do que Chartier denominou de apropriação ${ }^{11}$ dos discursos, no sentido hermenêutico. Nessa perspectiva, a apropriação consiste no que os leitores

[...] fazem com o que recebem, e que é uma forma de invenção, de criação e de produção desde o momento em que se apoderam dos textos ou dos objetos recebidos. Desta maneira, o conceito de apropriação pode misturar o

9 CHARTIER, Roger. “Textos, impressão, leitura”. In: HUNT, LYNN (org.). A nova história cultural. São Paulo: Martins Fontes, 2001.

10 GONDRA José Gonçalves. "Artes de civilizar”. Tese - (Doutorado em Educação) Universidade de São Paulo, 2000.

11 Roger Chartier tomou de empréstimo o conceito de apropriação de Michel de Certeau. 
controle e a invenção, pode articular a imposição de um sentido e a produção de novos sentidos". ${ }^{12}$

Logo, a construção de sentidos das modalidades do ato de ler e de escrever é resultante do encontro de dois mundos: o "mundo" do texto e o "mundo" do leitor. Portanto, o conceito de apropriação possibilita ao leitor, em grande medida, interpretar a multiplicidade de sentidos que ocorrem na recepção de um discurso médicoodontológico, representando o intervalo entre o objeto "original" e as suas reescritas. Chartier define o conceito de apropriação a partir do objetivo de elaborar

[...] uma história social das interpretações, remetidas para as suas determinações fundamentais (que são sociais, institucionais, culturais) e inscritas nas práticas específicas que as produzem. Conceder deste modo atenções às condições e aos processos que, muito concretamente, determinam as operações de construção do sentido (na relação de leitura, mas em muitas outras também) é reconhecer [...] que as categorias aparentemente mais invariáveis devem ser construídas na descontinuidade das trajetórias históricas. ${ }^{13}$

Portanto, a adoção desses conceitos nos possibilitou problematizar as formas de ler e os modos de prescrever a boca higienizada, "civilizada" e educada na Revista Salud y Sanidad, periódico no qual as imagens sobre os dentes e a boca apareciam como órgãos funcionais e naturalmente dispostos, escondendo as tramas de desejos e de sentimentos dos sujeitos. No periódico, deparamo-nos, também, com uma forte influência sobre a infância enquanto uma "instância" que pode ser disciplinada. Para

12 CHARTIER, Roger. Cultura escrita, literatura e história: Conversas de Roger Chartier com Carlos A. Anaya, Jesús A. R., Daniel Goldin e Antonio Saborit. Porto Alegre, Artmed Editora, 2001.

13 CHARTIER, Roger. Práticas de leitura. São Paulo: Estação Liberdade, 1996. 
compreender as imagens apresentadas, consideramos os conceitos de "biopolítica", "biopoder", "poder disciplinar" do filósofo Michel Foucault e o conceito de "civilidade" de Nobert Elias.

\section{"Melhor prevenir que curar": Higienismo e saúde bucal na Revista Salud y Sanidad, Colômbia (década de 1930)}

Em prol da modernização e urbanização de cidades colombianas, a exemplo de sua capital Bogotá, as agendas dos governantes da nação ${ }^{14}$ adotaram o tema de higiene social na busca de modelar os cidadãos. Os médicos lideraram esse processo, aliando as ações de saúde pública à criação de instituições que ganharam mais autonomia a partir da década de 1930, a exemplo do Conselho Nacional de Higiene, Conselho Superior de Sanidade da Colômbia e inspetorias de higiene. Estes possuíam como propósito regular os comportamentos sanitários, educar a população em matéria de higiene e castigar os infratores das normas sanitárias. ${ }^{15}$ A casa e a mãe também se tornaram responsáveis pelo cuidado da pátria a partir do cuidado com a infância. Maquinarias discursivas em prol da articulação mãe-filho tornaram-se recorrentes na literatura médica e pedagógica desse período, a exemplo da Revista Salud y Sanidad. Justificando o exercício de controle ortopédico sobre as crianças, através de novos métodos pedagógicos, o discurso sobre o amor materno pregava a domesticidade como um dos variados requisitos para a boa mãe, favorecendo a elaboração de um corpo materno sujeitado às novas verdades, nomeado e posto num "lugar civilizado": a casa.

14 Alguns presidentes da Colômbia da década de 1930: Enrique Olaya Herrera (19301934); Alfonso Lopez Pumarejo (1934-1938)

15 ARAMÉNDIZ, Miguel Antonio Suárez; MENDONZA, Edwin Andrés Monsalvo. La higiene y el progreso. La institucionalización de la burocracia sanitaria en Manizales. 19201940". Anuario de Historia Regional y de las Fronteras, v. 18, n.1, 2013, 99-125. 
Nesta direção, matérias veiculadas da Revista Salud y Sanidad abordaram a adoção dos princípios da higiene e do sanitarismo para transformarem o povo colombiano. Para tanto, mães e professores necessitavam estar conectados com os novos princípios de saúde para livrarem o povo colombiano do obscurantismo:

Verdadeiramente é sentida em nosso país a necessidade de difundir sem descanso os novos princípios da higiene, no qual o povo vive em absoluta ignorância. As mães ignoram o que devem fazer e o que devem evitar para que cresça saudável e feliz seu filho o qual depositam amor e ambições. Os mestres de escola pouco sabem de higiene porque nunca os ensinaram e, no entanto, devem transmitir a seus alunos seus conhecimentos e inculcar hábitos que eles devem praticar sempre e que decidirá a vida das futuras gerações escolares ${ }^{16}$

Na produção de uma "família ideal" para a Colômbia, uma série de espaços e de micropolíticas foram acionadas: a escola, a saúde, a vida doméstica, o gabinete dentário, o aprendizado através das redes de informação, enfim, todo um ambiente maquínico ${ }^{17}$ foi utilizado na fabricação do homem e da mulher necessários à República colombiana. A família adquiria uma nova "identidade", deixando aos poucos a vida sexual e as relações domésticas baseadas no interesse socioeconômico, passando a constituir um lar supostamente balizado na reciprocidade e no amor. Nascia um novo conceito de família - a burguesa - e emergia outro conceito para pensá-la: o de lar, dito como um espaço honrado e distante da desordem das ruas. Nesse ambiente, a ideia de ordem e de disciplina passa a ser evocada, como necessária para a manutenção do ambiente doméstico e da sua convivialidade com a rua.

16 "Nosso Propósito". Revista Salud y Sanidad, Bogotá-CO, n.1, março de 193, p. 3.

17 GUATARRI, Felix; ROLNIK, Suely. Micropolítica. Cartografias do desejo. Petrópolis: Vozes, 1998. p. 27. 
Diante desse e de outros discursos que circularam na Revista, identificamos a biopolítica governamental na busca de corpos saudáveis para a labuta, voltada a adotar um processo de higienização para agir sobre o povo, que era tido como incivilizado/ignorante/sujo. E para alcançar esse processo, algumas estratégias foram tomadas, dentre as quais destacamos o enlace entre a família e a escola, como importantes instituições que deveriam focar nas crianças para modificar o "futuro da nação". O discurso médico disciplinou os casais a cercar a vida do bebê com um cenário de paz para o seu bemestar físico e emocional. E nesse discurso, a domesticidade foi reforçada pelo mito do amor materno, constituindo uma "barreira de proteção" ao corpo dos rebentos. O amor materno circunscrevia mãe e filhos num ninho sentimental e a domesticidade tornava os membros da família mais solidários entre si, envoltos num casulo denominado de lar, investindo em padrões novos de comportamento como a ternura paternal, o respeito filial e a intimidade entre os cônjuges. Esse discurso visava garantir a obediência aos padrões de normalidade que afastassem a família dos estados patológicos, cristalizando um modelo de família muito próximo dos códigos cristãos.

Nesta direção, vamos ao encontro de estratégias exercidas para o controle da sociedade em prol do capitalismo, buscando força de trabalho e produção, tornando-se visível as marcas das relações de poder. Logo, deparamo-nos nesse momento retratado com o que Foucault denomina de "dominação política do corpo", que permite o controle das operações do corpo por meio da disciplina, fazendo com que os sujeitos sejam economicamente mais lucrativos, diminuindo sua capacidade política, tornando-os úteis e dóceis. ${ }^{18}$

Assim, os corpos infantis transformaram-se em alvo para implementação de práticas civilizatórias, que deveriam ser ensinadas por seus familiares e tutores, ressaltando a figura materna tida como responsável pela educação das(os) filhas(os). Novas estéticas de existência, do cuidado e do equilíbrio corporal são tecidas para a infância. Lições de civilidade e saúde deveriam ser ensinadas nas

18 FOUCAULT, Michel. Vigiar e Punir: nascimento da prisão. Petrópolis, RJ: Vozes, $38^{\mathrm{a} e d .,} 2010$. 
instituições escolares, com conteúdos, normas e adoção de práticas higienistas para civilizar as(os) escolares e o espaço escolar. Nessa biopolítica, cuidar da infância era contribuir para a prosperidade e felicidade da escola, da família e da pátria.

E em busca dessa nação "civilizada"19, as crianças colombianas foram induzidas a reproduzirem os hábitos propagados por médicos, dentistas profissionais e pedagogos. Era o governo das multidões, preocupado em sanitarizar as bocas e os dentes das crianças. Nesta perspectiva, a escola foi vista e dita como um espaço importante para incorporar no seu cotidiano métodos para instruir e moldar suas/seus alunas(os), bem como estreitar relações com professoras(es), alunas(os) e família. A escola precisava alfabetizar com o alfabeto da saúde. ${ }^{20}$ Informa a Revista:

Na realidade, cremos que a educação sobre higiene deve ser realizada pelas autoridades educativas ao invés das autoridades de higiene e que tal educação deve começar na escola. Na verdade, é tão importante para uma criança aprender no colégio a maneira de cuidar do seu corpo como é o desenvolvimento da inteligência ou da moral. Porque para uma mente muito brilhante um corpo débil ou enfermo é, para não dizer o pior, um grandíssimo obstáculo. "Mente sã em corpo saudável". ${ }^{21}$

19 Para Nobert Elias, civilizar faz referência a uma grande variedade de acontecimentos relacionados ao nível da tecnologia; à maneira como as pessoas se portam e se comportam socialmente; à forma de falarem e de alimentarem; ao desenvolvimento de conhecimentos científicos, às ideias religiosas e aos costumes ditos civilizados. Refere-se aos tipos de habitações ou as maneiras como os homens e mulheres vivem juntos, às formas de punição determinada pelo sistema judiciário ou ao modo como são preparados os alimentos. "Rigorosamente falando, nada há que não possa ser feito de forma "civilizada" ou "incivilizada". ELIAS, Nobert. O processo civilizador, volume 1: uma história dos costumes. 2aed, Rio de Janeiro: Zahar, 2011.

20 LUCENA, Meryglaucia Silva Azevedo. "Formar uma raça forte, capaz e digna da nossa estremecida pátria": a saúde do corpo infantil veiculada na revista do ensino da Paraíba (1932-1934). In: Anais II CONEDU, Campina Grande/PB, 2015.

21 BEVIER, George. "La higiene y la Asistencia Públicas". Revista Salud y Sanidad, Bogotá n.13 e 14, fevereiro de 1933: p. 8. 
Relacionada à pedagogia da higiene, percebe-se que os currículos escolares tornaram-se instrumentos para fazer efetiva a lei, para tanto, passaram a fazer parte do cotidiano escolar: atividades relacionadas com o cuidado do corpo (duchas, banhos e ginástica), normas de comportamento social e moral, maneiras de prevenir as enfermidades que eram o perigo para as crianças e inserção de temas de higiene nos edifícios, mobiliários, materiais escolares, nos horários, nas distribuições de tarefas, nas leituras, na escrita, nos exames escolares e na educação física ${ }^{22}$. Sobre a higiene escolar, a Revista deixa explícito que

O primeiro dever do mestre é cercar as crianças de um meio ambiente em que as coisas inanimadas ensinem tanto como os exemplos e mais que palavras. Por isso, não deve resignar-se ao estéril sacrifício de trabalhar em uma casa anti-higiênica. O único luxo de uma escola deve ser a limpeza e esta não se consegue sem pisos e paredes laváveis e água abundante. A luz do sol deve entrar em todas as partes, porque ela é o primeiro desinfetante e a melhor aliada da alegria. $\mathrm{O}$ ar puro deve ter as portas e janelas abertas para entrar e o ar gastado não deve ter obstáculos para sair. ${ }^{23}$

Para civilizar, higienizando e medicalizando os escolares, intervenções de saúde nas escolas foram implementadas e novas estruturas profissionais começaram a agir nesses espaços. ${ }^{24}$ Nesta direção, profissionais dentistas, médicos, políticos e pedagogos traziam em seus textos orientações/prescrições que receitavam formas e modos de viver para os sujeitos e colocavam em circulação discursos que formarão novas paisagens, novos espaços para os

22 GONZALES, Ángela Lucia Agudelo. Regenerar e higienizar. El papel desempeñado por la mujer y la niñez en Barranquilla 1900 - 1945. Memorias, Ano 5, n.9, p.94-109, 2008. 1932: p. 15.

23 “A Escola Higiênica”. Revista Salud y Sanidad, Bogotá, Colômbia, n.1, abril de

24 CORTÉS, Martha Cecilia Herrera. Modernización y Escuela Nueva em Colombia: 1914-1951. Santafé de Bogotá: Plaaza e Janes Editores Colombia, 1999. 
indivíduos. Referente à saúde bucal, percebe-se menção de profissionais dentistas nas escolas como parte integrante desse processo transformador na busca preventiva de males da saúde, ao mesmo tempo em que a Odontologia era posta como uma prática social e sanitária e submetida a regras de funcionamento, conforme afirma Botazzo. ${ }^{25}$

Portanto, podemos entender o corpo infantil como uma realidade biopolítica, a partir do qual foi foco de controle das políticas públicas do estado (visando ações econômicas, lucrativas), sendo a sua boca, também, objeto de medicalização. Considerando as figuras de médicos e dentistas atuando nas escolas, retratamos outra força de poder abordada por Foucault, o biopoder, que "só pode ser garantido à custa da inserção controlada dos corpos no aparelho de produção e por meio de um ajustamento dos fenômenos de população aos processos econômicos". 26

\section{"Salve você os dentes de sua criança": A Assistência bucal na infância}

Frente às ações preventivo-sanitaristas adotadas na década de 1930 por políticas e estratégias estatais para agirem nas crianças colombianas, destacaremos aqui as relacionadas à assistência bucal. As propagandas e discursos investigados na Revista são as classificadas como "populares", pois estas se dirigiam diretamente ao público consumidor e eram divulgadas com o objetivo de contribuir para o que Temporão chama de medicalização da vida cotidiana,

25 BOTAZZO, Carlos. Diálogos sobre a Boca. São Paulo: Hucitec, 2013, p.21.

26 FOUCAULT, Michel, Vigiar e Punir: nascimento da prisão. Petrópolis, RJ: Vozes, $38^{\mathrm{a} e d .,} 2010$ 
estratégia que compreende a divulgação de conhecimentos sobre saúde e doença. ${ }^{27}$

A saúde bucal, compreendida como um conceito complexo, não pode se restringir à 'saúde dos dentes', pois a mesma está relacionada tanto às condições biológicas quanto às subjetivas e culturais, que proporcionam aos indivíduos exercerem funções tais como: manducação, mastigação, deglutição, fonação, bem como pela dimensão estética, relacionada à autoestima e às condições que dizem respeito ao campo social, das relações humanas. ${ }^{28} \mathrm{~A}$ saúde bucal coletiva se estende para além do que a odontologia "pode pensar ou falar sobre a cavidade bucal dos homens, pois saúde bucal coletiva significa 'ver' o objeto odontológico de uma vertente não odontológica". ${ }^{29}$

Os profissionais dentistas desenvolviam a assistência bucal por meio de práticas relacionadas desde os tratamentos de enfermidades dentárias às ações de ensino e de autocuidado, sendo estas de suma importância para formação e realização de atividades que colaboram com o bom desenvolvimento da saúde bucal das crianças. Assim, identificamos nas fontes deste estudo, as prescrições de profissionais dentistas para a infância desde o pré-natal, passando pelos primeiros dias de vida e pela fase escolar, tendo a mãe a responsabilidade sobre esses. $\mathrm{O}$ amor materno, como uma construção histórica do século $\mathrm{XIX}^{30}$ se instalava na família colombiana modificando o entrelaçamento entre mãe e filhos, e mudando a posição que a criança ocupava na hierarquia de valores da família. Em nome do amor materno, era pregada, por médicos, pedagogos e juristas, a permanência da mãe no ambiente doméstico, circunscrevendo-a a uma série de tarefas pedagógicas e nutricionais. Além do ambiente familiar, esse discurso também circulou fortemente

27 ROLIM, Marlon Silva. Se é Bayer é Bom: divulgação comercial e científica alemã na Revista Terapêutica e em o Farmacêutico Brasileiro (1921-1945). Dissertação- (Mestrado em História das Ciências e da Saúde) Fundação Oswaldo Cruz, 2011, p. 46.

28 NARVAI, Paulo Capel; FRAZÃO, Paulo. Saúde Bucal no Brasil: Muito além do Céu da boca. Rio de Janeiro: Editora Fiocruz, 2008.

29 BOTAZZO, C. op. Cit. p. 22

30 BADINTER, Elisabeth. Um Amor conquistado: o mito do amor materno. Rio de Janeiro: Nova Fronteira, 1985. 
no espaço escolar, com práticas supervisionadas pelos dentistas e também professores.

Visualizamos nos conteúdos da Revista Salud y Sanidad a presença da responsabilização materna, onde a mãe tida como responsável familiar deveria ser um guia para cuidar e reproduzir prescrições que lhes são impostas na busca de filhos fortes, bonitos, hábeis e com boa dentição. O discurso do dentista atacava o mal pela raiz, conclamando as mães a cuidarem do sorriso dos filhos, evitando, portanto, sequelas futuras, a exemplo de uma boca desdentada. Desejava descartar as enfermidades da idade adulta, protegendo a criança e, por sua vez, educando os pais nesse sentido.

Os serviços de assistência eram poucos e, muitas vezes, restritos ao ambiente escolar e aos dispensários, razão pela qual há um regulamento discursivo em torno da mãe e de seus cuidados com a saúde bucal de seus filhos. Em um dos artigos publicados, deparamo-nos no título com a seguinte chamada: "Salve você os dentes de sua criança" 31 , descrevendo em seu conteúdo a atenção que as mães deveriam ter com seus filhos e a responsabilidade de os levarem aos dentistas para não perderem seus dentes. Há uma regulamentação discursiva em torno da escovação e do cuidado com a ingestão da sacarose, conforme adverte o artigo "Dentes Normais", no qual a escovação deve fazer parte do diário do bebê desde que surge o primeiro dentinho: "Escovando os dentes cuidadosamente duas vezes ao dia com um bom creme dental suaviza a pasta de alimentos em decomposição que se amontoa com tanta rapidez e cai facilmente com a escova" 32 .

O filho, seus dentes e o seu corpo, assim como a sua educação, passaram a ser prioridades, pois o amor materno encarregar-se-á de colocar os interesses da criança acima de outros projetos pessoais da mãe, que se abnega pela família, cuidando-a como uma tarefa especificamente sacerdotal. Como "guardiã" do lar, era capaz de renunciar a ornamentação do seu próprio corpo, como o uso de roupas da moda ou de distrações consideradas "fúteis" (como

31 WISAN, J. M. Salve você os dentes de sua criança. Revista Salud y Sanidad, Bogotá-Colômbia, ano VI, n. 54, fevereiro de 1937, p. 4.

32 Dentes Normais. Revista Salud y Sanidad, Bogotá-Colômbia, ano III, n. 25 e 26 , janeiro e fevereiro de 1934, p. 31. 
o cinema e o teatro que poderiam dar "maus exemplos" aos filhos), para se dedicar ao serviço do lar.

Em Salud y Sanidad, a figura materna era tida como responsável desde a composição embrionária fetal, onde a mesma deveria ter cuidados alimentares e nutritivos para que seu filho tivesse um desenvolvimento vigoroso, como podemos verificar no seguinte trecho:

Como é sabido, para a completa nutrição do embrião é preciso uma alimentação saudável e nutritiva, de parte da mãe, rica em sais de cálcio e de ferro, cuja resultante será um sangue vigoroso, que é o que desenvolverá o folículo dentário, que começa a consolidar-se na oitava semana da vida intrauterina. ${ }^{33}$

Antes mesmo de a criança nascer, as mães deveriam atentarse com a alimentação. O embrião emergia como um sujeito que precisava ser constantemente visto, cuidado e vigiado para ter ossos fortes (incluindo os dentes) ${ }^{34}$. Ao nascer, os cuidados eram redobrados. Esta tônica é o que observamos em uma advertência expressa para as mães: "A precaução mais necessária deve ser uma dieta apropriada à idade e ao estado de saúde da criança. $\mathrm{O}$ mesmo que uma limpeza rigorosa da boca e dos dentes praticada pela mãe" 35 . Como parte de um programa mais amplo, políticos, médicos e educadores procuravam dar visibilidade a novos sentimentos voltados para o lar. Docilidade, carinho e cuidado são prescrições médicas que deviam ser subjetivadas pela família, particularmente pela mulher. A maternidade e a domesticidade são vistas como sentimentos ou práticas afetivas que reforçam as relações entre os seus membros. Nessa época histórica, as famílias passaram a ser alimentadas por uma

33 "Puericultura e Higiene dentales", Revista Salud y Sanidad. Bogotá-Colômbia, n.55, março de 1937, p. 16-22.

34 Dentes Normais. Revista Salud y Sanidad, Bogotá-Colômbia, ano III, n. 25 e 26, janeiro e fevereiro de 1934, p. 31.

35 Dentes Normais. Revista Salud y Sanidad, Bogotá-Colômbia, ano III, n. 25 e 26, janeiro e fevereiro de 1934, p. 31. 
indústria de consumo e de mídia (dentrifícios, escovas de dentes, próteses, dentes revestidos de ouro, produtos para combater a halitose) nunca vista antes na história da Colômbia e da América Latina, buscando criar um "tipo ideal" de família para cuidar da saúde e do bem-estar dos seus filhos.

No discurso da Revista Salud y Sanidad, percebe-se que houve a substituição de uma economia baseada apenas na "moral" e nos costumes para uma economia de mercado, da irrupção de simulacros que provocaram a mudança de valores e de comportamentos. A domesticidade, entendida como a imagem que a família tem de si mesma enquanto unidade emocional, deveria ser preservada e protegida dos "elementos intrusos", isolada do exterior. A mãe deveria cuidar da "completa nutrição" do feto para que o mesmo se desenvolvesse bem. A base emocional do casamento burguês ligava muito mais que o casal: envolvia os filhos neste ambiente sentimental, legitimando o discurso político-pedagógico e a construção de cidadãos amantes à pátria.

Supervisionar e colocar as crianças para escovarem sua dentadura era uma prática de higiene que buscava evitar nas crianças futuros problemas mais graves com a dentição. A cárie emergia como um problema social e, para tanto, os olhares atentos dos pais são acionados constantemente. "A escova de dentes deve passar pelo interior e pelo exterior da dentadura: para cima e para baixo, recorrendo toda a superfície dentaria" ${ }^{36}$. Essa prática era uma ação imprescindível para uma boa saúde familiar, não apenas do filho. A escova, como uma biotecnologia voltada à saúde bucal, era um instrumento "político" de cuidar da nação, uma parte do processo civilizatório.

Governo e maternidade unem-se para "civilizar" a infância. A boca e a escova deveriam ter uma anatomia própria e, para tanto, a mãe, o dentista e os professores são acionados para a eleição da melhor escova, aquela "que permita alcançar as regiões mais

36 WISAN, J. M. "Salve Usted los dientes de su niños". Revista Salud y Sanidad, Bogotá-Colômbia, ano VI, n.54, fevereiro de 1937, p. 7. 
inacessíveis da dentadura e manter as gengivas perfeitamente saudáveis" ${ }^{\prime 37}$.

O mito do amor materno determinava valores sociais e sedimentava determinados paradigmas culturais, fechando a mulher em casa com a chave da domesticidade, da mãe-amor, já mitificada pelo estatuto naturalizante do discurso burguês. A família era construída pelo discurso romântico-burguês como um território de afeição entre os cônjuges e entre pais e filhos. Casa e escola estão, agora, cercadas por regras sanitárias, por regimes de ocupação do tempo (recreio, sala de aula, biblioteca, dever de casa) e pela criação de modelos ideais de sujeito baseados na desenvoltura física (ginástica, esportes, educação física, dentição), nos preceitos morais e religiosos. ${ }^{38}$ Aos poucos, a escola primária se convertia num instituto de ortopedia física e psíquica, em que colaboravam quatro agentes: a família, o professor, o médico e o dentista. ${ }^{39}$

Nessa atmosfera, a infância adquiriu um valor e uma importância singulares, pois os pais passaram a se preocupar com a sua educação, com a valorização do caráter dos filhos, com as "coisas menores" do seu corpo, a exemplo do dente e do regime alimentar que pudesse prejudicar sua dentadura. É uma estratégia de poder do Estado que vê na criança um "soldado" em potencial, militarizando o seu corpo através de exercícios corporais, inserindo disciplinas como Ginástica e Exercícios Físicos nos currículos das escolas públicas. A criança foi "amarrada" a uma teia de discursos e presa psicológica, financeira e emocionalmente à "célula-mãe" da sociedade: a família. ${ }^{40}$

Nos espaços escolares, as práticas de escovação constituíam a rotina de escolares, cenário no qual os professores eram responsáveis por supervisionar o asseio dos alunos e a escovação, que se tornaram uma prática demonstrada passo a passo para ser aprendida e adotada na higiene das crianças. Nesses cenários, também se encontravam

37 WISAN, J. M. "Salve Usted los dientes de su niños". Revista Salud y Sanidad, Bogotá- Colômbia, n.54, fevereiro de 1937, p.8.

38 ORTEGA, Francisco. O corpo incerto. Rio de Janeiro: Garamond, 2008. p.31

39 COUTO, Miguel. In: OLIVEIRA, Antônio Campos de. Assistência dentária à infância. Anais do I Congresso Brasileiro de Odontopediatria. Recife, p. 22.

40 SHORTER, Edward. A formação da família moderna. Lisboa: Terramar, 1994, p. 28 
dentistas escolares que eram responsáveis por ações de prevenção e também tratamentos dos dentes dos escolares.

\begin{abstract}
Deve se ensinar as crianças a maneira adequada de usar a escova de dentes. Os dentistas e os mestres estão assumindo esta tarefa. Aconselha-se o emprego de uma escova pequena com espaços entre as cerdas, escova que permita alcançar as regiões mais inacessíveis da dentadura e manter as gengivas perfeitamente saudáveis. ${ }^{41}$
\end{abstract}

Alcançar as regiões mais inacessíveis da dentatura. Era este o objetivo de uma boa escova e de uma perfeita escovação. Mas, também, o discurso queria atingir as regiões mais inacessíveis dos mestres, das mães e dos pais. Atingir suas sensibilidades de autoridade em relação à criança, levando-os a introjetarem os dispositivos pedagógicos do discurso higienista. Regiões inacessíveis dos pais, mestres, dentistas, do governo dos outros. A assistência bucal não estava restrita, apenas, à higiene dos dentes. A boca compreendia uma geografia muito mais ampla que incluía a língua, os lábios, o hálito e, inclusive, a fala. A geografia da boca passou a ser censurada pelo olhar e pelo sentir do outro que pode perceber sinais de sujeira, cáries, mau hálito e feridas linguais. Falar palavrões, impropérios, não era uma característica de uma criança bem-educada. Aos poucos, ações proibitivas são acionadas e construídas como antissocial, tais como "comer de boca aberta, comer rápido, comer demasiado devagar, cuspir, arrotar, falar alto, falar errado, xingar, o beijo apaixonado ou em público"42. Ver essas coisas passou a ser descrito como feio, animalesco. A boca foi reinventada como objeto da visão e reprimida pelas normas sociais. Assim, coisas simples passaram a ser "tolhidas, limitadas, condicionadas, reprimidas, e a

41 WISAN, J. M., "Salve Usted los dientes de su niños". Revista Salud y Sanidad, Bogotá- Colômbia, n.54, fevereiro de 1937, p.6.

42 KOVALESKI, Douglas Francisco; FREITAS, Sérgio Fernando Torres de; BOTAZZO, Carlos. Disciplinarização da boca, a autonomia do indivíduo na sociedade do trabalho. Ciências e saúde coletiva. v. 11, n. 1, 2006, p. 97-103. 
boca tornou-se alvo especial de repressão. Um centro de prazer e repressão". ${ }^{43}$

A aparência conta e denuncia as práticas de higiene do sujeito e da família. Sob essa perspectiva, a Revista Salud y Sanidad publica em março de 1933 uma novelinha chamada "Por um beso de tu boca", mostrando os perigos do beijo nas crianças e como esse ato, às vezes materno e ingênuo, pode provocar doenças várias na população. A novela conta que Rosa teve um menino rosado, gracioso, bondoso e primoroso. Porém, certa vez o garotinho ficou sozinho e uma tísica, talvez mal intencionada, veio e aplicou-lhe um beijo. Não demorou para que o garotinho se tornasse pálido, triste, chorão, raquítico e esquálido. Estava tuberculoso! Moribundo, o antes gracioso garoto se tornava cada dia mais triste, até que morreu. A boca que beija tornou-se a boca que mata, a boca que suja e leva o homem à cova! No túmulo do garoto, um médico prescreveu uma bula para as mães, alertando-as sobre os perigos do beijo. Para proteger seus meninos, as mães que tinham contato com essa história começaram a fazer roupas e cartazes para os seus filhinhos com a seguinte frase: "no me beses". 44

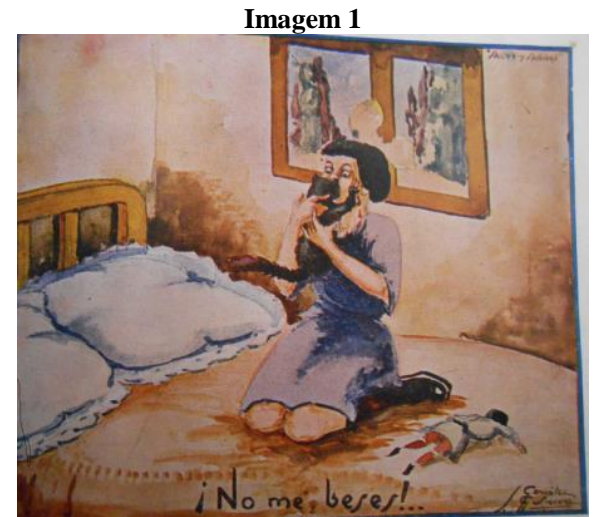

Capa da Revista Salud y Sanidad, março e abril de 1934.

43 Idem, ibidem, p. 101.

44 "Por um beso de tu boca". Revista Salud y Sanidad, Bogotá-Colômbia, n.15, março de 1933 , p. 41. 
Na Colômbia, como também em outras nações, a exemplo do Brasil, as crianças são constantemente alertadas dos reais perigos do beijo, propagador da tuberculose e de outros males. Para evitar o contágio, as pessoas, incluindo mães e filhos, tinham que portar bons hábitos higiênicos, "como lavar as mãos com frequência, não comer alimentos estragados, não beber água contaminada e, claro, não beijar pessoas enfermas. Pelo beijo, a doença passava de uma pessoa para outra com enorme facilidade" 45 .

Uma crítica tecida aos dentistas e, muitas vezes, repetida pelos professores nas salas de aula, é que os mesmos tendiam a reduzir o corpo do sujeito ao dente, à boca. O corpo do sujeito aparecia fragmentado, reduzido a um conjunto de membros (olhos, vísceras, bocas, mãos, pés, orelhas, narinas) cirurgicamente dissociados de seus contextos, simplificados, divorciados dos organismos ao qual pertencem. ${ }^{46} \mathrm{O}$ dente era tratado, escovado, cirurgiado, mas quase sempre essa prática da dentística está dissociada do corpo do sujeito como uma máquina, não apenas como uma boca.

\section{Considerações Finais}

Compreender a saúde bucal como uma estratégia adotada pelo Estado colombiano em prol da modernidade de seus cidadãos, desdobra-se no entendimento de que as crianças foram alvos de ações assistencialistas dos cirurgiões dentistas e de métodos normativos. Estes métodos são encontrados: 1) em atividades familiares, sendo a mãe a principal responsável por modelar seus filhos; 2) em atividades escolares, cartografia na qual as professoras e professores eram

45 SANTOS, Alexandro dos. "Um corpo são, em uma mente sã": O ensino de Higiene e Educação Física no Instituto Pedagógico - Campina Grande - PB (Décadas de 1920 e 1940). 2016. 80f. Monografia. (Graduação em História). Universidade Federal de Campina Grande, Campina Grande - PB.

46ORTEGA, Francisco. O corpo incerto. Rio de Janeiro: Garamond, 2008. p. 111. 
responsáveis por ensinar e educar os futuros cidadãos; 3) em atividades profissionais, nas quais se situavam os dentistas, inseridos nos espaços escolares para assistir, cuidar e prevenir doenças, promovendo regulamentos sobre corpos saudáveis por meio de avaliações clínicas e de incentivo a práticas como a escovação.

Verificamos a divulgação da escovação como uma prática de limpeza bucal como uma parte do caminho civilizatório. Portanto, nota-se nessas atividades implementadas por dentistas a ênfase do poder Estatal, das instituições políticas e dos saberes científicos da área da saúde, que acabam se constituindo como instrumento de controle social e construtores de uma identidade nacional. Assim, encontramos um processo de medicalização da sociedade que resultou em relações intrinsecamente hierárquicas e disciplinadoras.

A saúde bucal emergia como um tipo de assinatura de si. A boca, como um lugar onde vários saberes se cruzam, compreendia uma topografia muito mais ampla que incluía a língua, os lábios, o hálito, a manducação, o prazer e perpassava o corpo biológico e as construções culturais. Era preciso mostrar-se saudável, uma atitude que funcionava como sinalizador social em resposta aos modelos emergentes de civilidade. Portanto, ensinar os escolares como higienizar e cuidar dos seus dentes constitua uma das estratégias de governo para formar cidadãos civilizados e uma sociedade dita moderna. Assim, a participação da mãe, das professoras e dos dentistas como instrumentos regularizadores e de vigília compunha atividades caracterizadas pelo poder disciplinar, pelo biopoder, marcado por ações pautadas por regras higiênicas, preceitos morais e religiosos para criar modelos ideais de sujeito na Colômbia. Dessa forma, "era melhor prevenir que curar", evitando, assim, los besos de su boca.

RECEBIDO EM: 01/03/2017

APROVADO EM: 01/06/2017 